\title{
The percentage effect of slag on the behavior of a high performance concrete
}

\author{
Chaher Rihia ${ }^{1, *}$ and Houria Hebhoub ${ }^{1}$ \\ ${ }^{1}$ LMGHU Laboratory, Skikda University, Algeria.
}

\begin{abstract}
The purpose of this study is to determine the feasibility of the partial replacement of cement with recycled fines in a high performance concrete whose purpose is to minimize the use of Portland cement and reduce the environmental impact of this waste. In the context of which, we used the fines of the granulated slag from El Hadjar-Annaba as a partial replacement of cement with substitution rates of $10,15,20 \%$, and to study the behaviour in the fresh state (density and workability) and the mechanical performances (compressive and flexural tensile strength) and dimensional variation in the cured state, and then compared the results found with control samples of $0 \%$ substitution rate. Subsequent to which, it can be concluded that the introduction of recycled fines reduces the density and workability and improves the concrete's mechanical performance.
\end{abstract}

\section{Introduction}

The discovery of high performance concrete makes it possible to produce a material with a high level of efficiency compared with the ordinary concrete, and of high performance with regards to the hardness by use of superplasticizers with low $\mathrm{E} / \mathrm{C}$ ratios. The partial substitution of a cement quantity in this material improves several physical and mechanical properties. The objective of this study is to realize a High Performance Concrete based on the addition that is the blast furnace slag.

\section{Characterization of materials}

The materials used in this study are as follows:

- CPJ-CEM II / A 42.5 Cement with a limestone addition originating from the cement factory of El-Hama Constantine, with an absolute powder density of 3.01 $\mathrm{g} / \mathrm{cm} 3$.

- The slag fines are obtained by grinding in a standardized ball grinding machine of granulated slag, passing it through a sieve of $0.080 \mathrm{~mm}$ and greater than $90 \%$.

- Rolled nature siliceous dune sand of 0/1 class, originating from Oued Zhor, Collo -Skikda.

- Crashed quarry sand of 0/4 class, originating from Ben Azzouz -Skikda.

- Crushed gravel of 4/8 Class, originating from Ben Azzouz -Skikda.
- Crushed gravel of 8/16 Class, originating from Ben Azzouz -Skikda.

- The adjuvant used is SIKA VISCOCRETE 3045, a plasticizer reducing water.

Table 1. The results of the characterization tests.

\begin{tabular}{|c|c|c|c|c|}
\hline Physical properties & $\begin{array}{c}\text { S } \\
\mathbf{0 / 1}\end{array}$ & $\begin{array}{c}\mathbf{S} \\
\mathbf{0} / \mathbf{4}\end{array}$ & $\begin{array}{c}\mathbf{G} \\
\mathbf{4 / 8}\end{array}$ & $\begin{array}{c}\mathbf{G} \\
\mathbf{8 / 1 6}\end{array}$ \\
\hline Bulk density $\left(\mathrm{g} / \mathrm{cm}^{3}\right)$ & 1.55 & 2.60 & 2.67 & 2.68 \\
\hline Absolute density $\left(\mathrm{g} / \mathrm{cm}^{3}\right)$ & 2.50 & 2.72 & 2.72 & 2.76 \\
\hline Sand equivalent (\%) & $\begin{array}{c}73.0 \\
7\end{array}$ & 72 & -- & -- \\
\hline Fineness modulus (\%) & 1.60 & 3.04 & -- & -- \\
\hline Fines content (\%) & 5 & 16 & 3.39 & 3.12 \\
\hline
\end{tabular}

Table 1. The chemical composition of cement and slag fines.

\begin{tabular}{|c|c|c|}
\hline Chemical composition & CEM II 42.5 & Slag fines \\
\hline $\mathrm{CaO}$ & 55.86 & 44.36 \\
\hline $\mathrm{Cl}$ & -- & -- \\
\hline $\mathrm{AL}_{2} \mathrm{O}_{3}$ & 6.13 & 8.78 \\
\hline $\mathrm{Fe}_{2} \mathrm{O}_{3}$ & 3.12 & 2.71 \\
\hline $\mathrm{SiO}_{2}$ & 27.00 & 41.20 \\
\hline $\mathrm{CaO}$ libre & 0.88 & -- \\
\hline $\mathrm{MgO}$ & 0.94 & 4.28 \\
\hline
\end{tabular}

\footnotetext{
* Corresponding author: rihiachaher@gmail.com
} 
The results of the characterization tests are shown in Tables 1 and 2 .

- The density of slag fines is lower than the cement one. - The cleanliness marked by the sand equivalent test is 73.07 and $72 \%$ for dune and quarry sand respectively, in accordance with the NF EN 933-8 Standard; it represents a sign that the used sands are clean and perfectly suitable for high quality concretes.

- The fineness module of the dune sand is 1.60 indicating very fine sand, which is characterized by a facility implemented at the probable detriment of the resistance and a high water demand, the opposite for the quarry sand with a higher fineness module.

- The silica content in the slag fines is slightly higher in comparison with the cement, which indicates long-term high strengths.

- The four types of aggregates are characterized by a continuous particle size distribution.

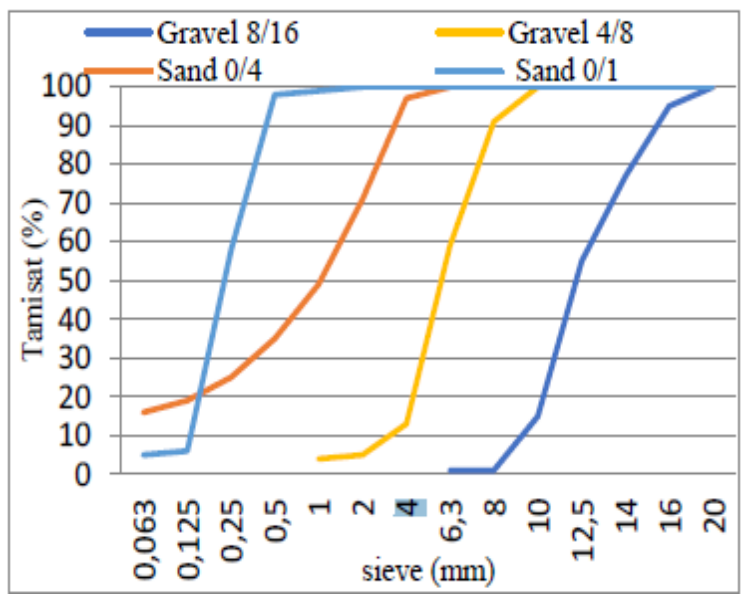

Fig. 1. Particle size curves.

\section{Experimental program}

In the experimental program, we introduced the slag fines in the formulation of a High Performance Concrete with rates $(0 \%, 10 \%, 15 \%$ and $20 \%)$, with the fixed parameters, which are the dosage in water, adjuvant, sand and gravel.

The formulation is made by the SHERBROOKE University method and the tests on the concrete in the fresh state are the density and workability, and the tests performed on the hardened concrete are measured by the compressive strength and the flexural tensile strength at the age 7 and 28 days and dimensional variation. The high performance concrete studied in this experimental study are identified as follows:

-BHP (T): Reference concrete with 0\% slag fines.

-BHP (10): Concrete with 10\% slag fines.

-BHP (15): Concrete with 15\% slag fines.

-BHP (20): Concrete with 20\% slag fines.

\section{Results and discussion}

\subsection{Density}

The minimum density is obtained by a rate of $20 \%$ (Figure 2), the increase of slag fines leads to a decrease in density (the slag density is lower than the cement one), these results are compliant with those found by.

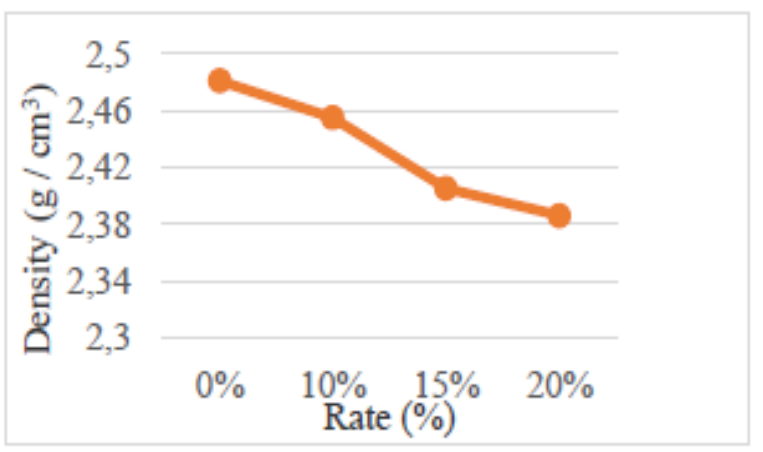

Fig. 2. The density variation as per the substitution rate function.

\subsection{Workability}

The workability decreases with the increase of the substitution rate (Figure 3), this is explained by the negative effect of the slag fines on the compatibility of the cement-superplasticizer system by accelerating the decrease in the concrete fluidity [1].

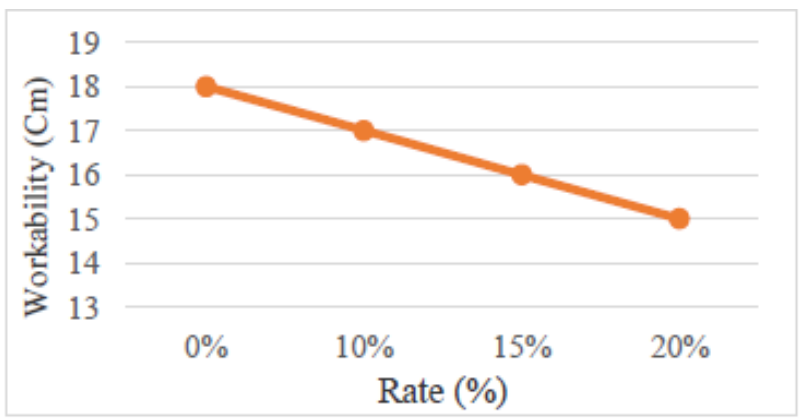

Fig. 3. Variability of workability according as per the substitution rate.

\subsection{Compressive strength}

The compressive strength (Figure 4) increases with the increase in the slag fines substitution rate for all ages to a maximum strength of $47.92 \mathrm{MPa}$ at 7 days with $10 \%$ substitution and $60.08 \mathrm{MPa}$ at 28 days with $15 \%$ substitution, these results are confirmed by Boukendakdji et al, 2009 [2]. This is due to the effect of fillers and the pozzolanic reaction of the slag. 


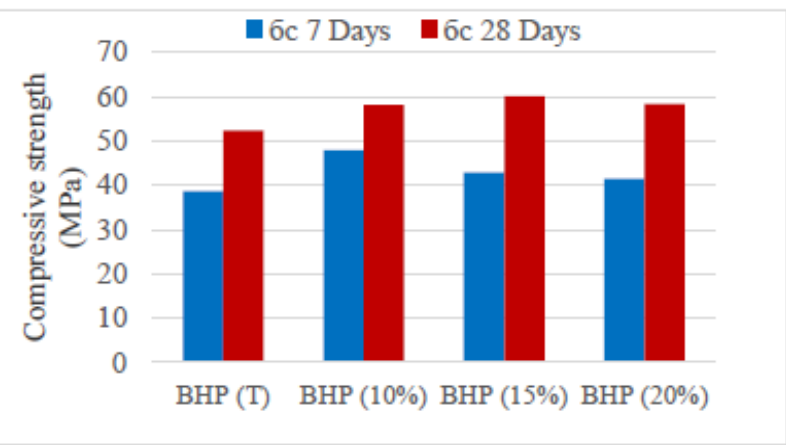

Fig. 4. The compressive strength of the concretes studied.

\subsection{Flexural tensile strength}

At 28 days, the introduction of slag fines leads to increase the resistance of the control concrete (Figure 5) and the best tensile performances are given by concrete with a $15 \%$ substitution rate regardless the age.

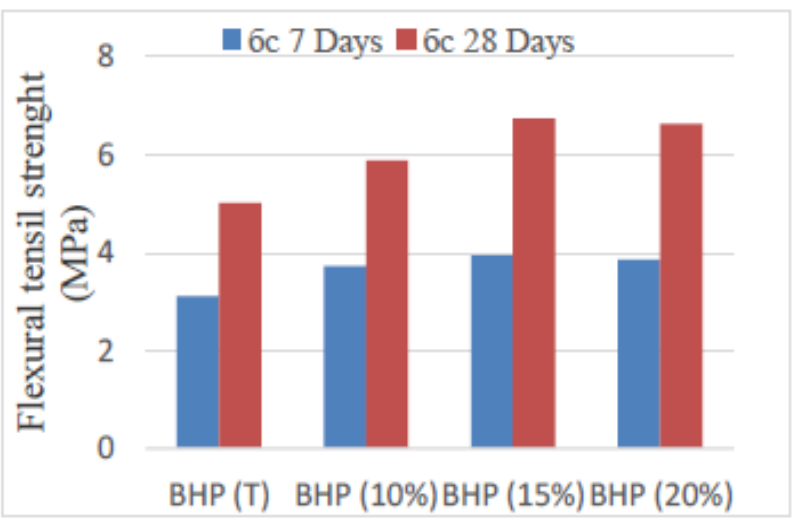

Fig. 5. The tensile strength of the concretes studied.

\subsection{Shrinkage and loses in weight}

The introduction of recycled fines leads to a decrease of $10 \%$ in the shrinkage of concrete (Figure 6). These results are consistent with those obtained by Gameiro et al, 2014 [3] and contrarily to those obtained by song et al, 2001 [4] whereat it was realized that the increase in the percentage of slag fines increases the longtermshrinkage, the fat of which is observed on the $12 \%$ substitution rate concrete.

The maximum weight loss is obtained for a $20 \%$ substitution rate (Figure 7 ), the introduction of $10 \%$ of slag fines results in a decrease of the weight loss.

\section{Conclusion}

According to this study, we can conclude that:

- Increasing the slag fines causes a decrease in density;

-The fresh state test shows that the slag fines reduce the concrete workability;

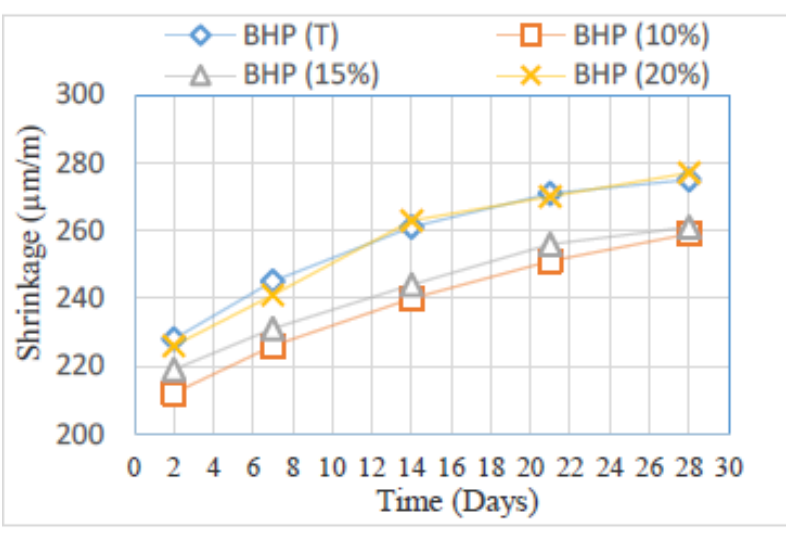

Fig. 6. Variation of withdrawal according to the substitution rate.

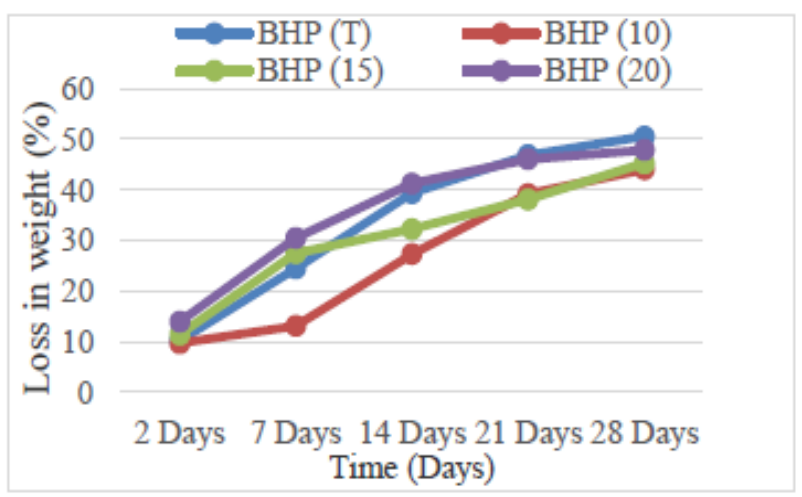

Fig. 7. Variation of the weight loss according to the substitution rate.

- The method of formulation of the Sherbrooke University is applicable for the manufacture of the High Performance Concrete based on the slag fines of El-hadjar;

- The introduction of slag fines leads to an increase in compressive strengths;

- The substitution of $15 \%$ of the slag fines gives a better tensile strength regardless the age;

- The introduction of $10 \%$ of the slag fines leads to a decrease in shrinkage and loss in weight.

Finally, we can highlight the possibility to use the slag fines as a substitute for cement in high performance concrete.

\section{References}

1. Yang J.W., Wang Q., Yan P.Y., Zhang B. Key Engineering Materials, 539, 235 (2013).

2. Boukendakdji O., Kenai S., Kadri E. H., Rouis F. Construction and Building Materials, 23, 2593 (2009).

3. Gameiro F., de Brito J., Correia de Silva D. Engineering Structures, 59, 654 (2014).

4. Sang H. W., Byun K. J., Kim S. H., Choi D. H. International Symposium on Self-Compacting Concrete, Tokyo, 413 (2001). 